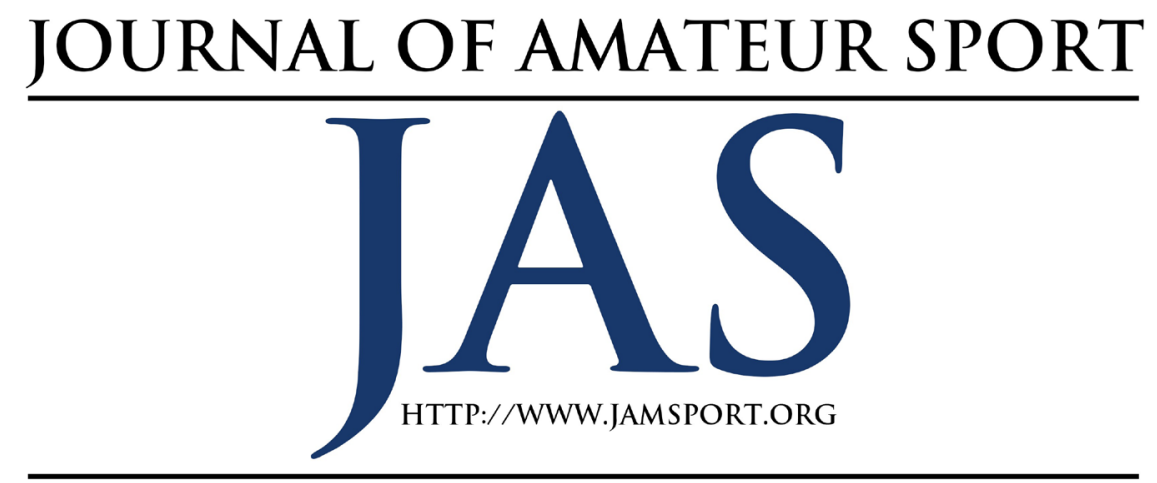

\title{
An Examination of Sport Motivation, Motivational Climate, and Athlete Burnout within the Developmental Model of Sport Participation
}

\author{
William D. Russell, PhD \\ Missouri Western State Univesity
}

\begin{abstract}
Young adults' retrospective recall of high school sport motivations, motivational climate, and burnout were compared based on whether they fit the "specializer" or "sampler" track within the Developmental Model of Sport Participation (DMSP, Côté \& Fraser-Thomas, 2007). College students $(N=156)$ fitting these two DMSP tracks completed their recall of sport motivations (Sport Motivation Scale-II), motivational climate (Motivational Climate Scale for Youth Sports) and athlete burnout (Athlete Burnout Questionnaire). Separate one-way MANOVAs comparing samplers $(n=113)$ and specializers $(n=43)$ on these variables were not significant $(p>$ $.05)$. Multiple regression analyses showed amotivation and intrinsic regulation were significant positive and negative predictors (respectively) of burnout dimensions. Performance climate was predictive of exhaustion and sport devaluation, while mastery climate negatively predicted reduced sense of accomplishment. Although Self-Determination Theory was further supported in examining burnout, lack of differences across DMSP track suggests that samplers and specializers in non-elite, amateur youth sport settings do not differ in burnout.
\end{abstract}

Y outh sports in the United States are immensely popular, and provide numerous positive benefits (Fraser-Thomas et al., 2005), many of which are unique to sports compared to other organized youth activities (Hansen et al., 2003). Yet, many youth sports are evolving into continual, regimented, adult-organized programs focused on outcome (Gustafsson, Kenttä, Hassmén, \& Lundqvist, 2007). Also evident in such settings are perpetual training cycles, characterized by greater competitiveness, increased parental involvement 
and expectations, and reduced athlete recovery, all of which may foster burnout (Gould \& Diffenbach, 2002; Gustafsson, Kenttä, Hassmén, Lundqvist, \& Durand-Bush, 2007). Such burnout may be related to early specialization (Baker, 2003; Strachan et al., 2009), which typically involves a single, year-round sport focus. Many specialization concerns exist, such as increased athlete anxiety (Gould, 2010), sport injury (Jayanthi et al., 2015), and burnout (Fraser-Thomas et al., 2005; Harris \& Watson, 2014). Parents and coaches often view early specialization as essential for sport success (Baker, 2003), yet research suggests that youth who delay sport specialization are more likely to have greater success in their sport compared to those who specialize early (e.g., Moesch et al., 2011).

Because burnout is a growing concern (Gustafsson, Kenttä, Hassmén, \& Lundqvist, 2007; Raedeke \& Smith, 2009), gaining greater understanding of burnout is important. Athlete burnout is a progressive, multidimensional syndrome characterized by (a) emotional and physical exhaustion from intense training and competition; (b) reduced sense of accomplishment, with athletes performing below expectations; and (c) sport devaluation, or a decreased caring about one's sport involvement (Raedeke \& Smith, 2001). Burnout prevalence is rising due to greater sport pressures (Gustafsson et al., 2011), yet while burnout has been studied in adults (e.g., Holmberg \& Sheridan, 2013), less is known about youth sport burnout. Youth athletes often report low-to-moderate burnout levels (Gus- tafsson, Kenttä, Hassmén, \& Lundqvist, 2007), but it is more prevalent in later adolescence (Harris \& Watson, 2014). Specializers show higher physical/emotional exhaustion than multi-sport youth athletes (Strachan et al., 2009), and youth who experience earlier and greater training volumes are more likely to drop out of sport (Wall \& Côté, 2007).

Burnout also is linked to athletes' reduced self-determined motivation (Cresswell \& Eklund, 2005a, 2005b; Holmberg \& Sheridan, 2013). In particular, Self-Determination Theory (SDT; Deci \& Ryan, 1985) has been central in examining motivation and burnout in adult athletes (Cresswell \& Eklund, 2005a; Li et al., 2013; Lonsdale et al., 2009) as well as youth athletes (Harris \& Watson, 2011). According to the Basic Needs Theory, (a subtheory of SDT), people are motivated to satisfy the basic needs of being autonomous (volitional decision making), demonstrating competence (feeling effective in producing desired outcomes), and experiencing relatedness (meaningful connections) to others (Ryan \& Deci, 2000). Also proposed by SDT is that motivation falls on a continuum from amotivation to intrinsic motivation, with extrinsic participation motives falling between these two continuum ends (Deci \& Ryan, 2000). Various extrinsic and intrinsic motivations are on this continuum and include (from least to greatest) self-determined participation motives: external regulation; introjected regulation; identified regulation; integrated regulation; and intrinsic motivation. As one moves from amotivation towards intrinsic 
motives, their motivation becomes more self-determined. Burnout research using the SDT framework has shown a positive relationship between athlete burnout and extrinsic motivation (Holmberg \& Sheridan, 2013) and amotivation (Cresswell \& Eklund, 2005a, 2005b; Gould et al., 1996; Raedeke \& Smith, 2001), and a negative relationship between athlete burnout and intrinsic motivation (Holmberg \& Sheridan, 2013; Raedeke \& Smith, 2001).

In addition to athletes' motivations, the motivational climate can influence burnout. Perceived motivational climate is created by key individuals (e.g., parents and coaches) who influence athletes, and refers to goal structures and expectations that shape an individual's views on success (Ames, 1992). Empirical interest has been on examining the coach's role in forming task (mastery)- and ego (performance)-involving climates and athletes' subsequent affective and behavioral outcomes (Duda \& Balaguer, 2007; Reinboth \& Duda, 2004). In task-involving climates, coaches focus on learning and effort, offer ability-matched task variety, and encourage cooperation. By contrast, coaches in ego-involving climates emphasize winning, normative ability, teammate rivalries, and reduced autonomy (Ntoumanis \& Biddle, 1999). As such, task-involving climates are linked to more adaptive athlete behaviors and positive emotional responses (Vitali et al., 2015).

Burnout prevention requires matching sport environments with athletes' developmental needs (Raedeke \& Smith, 2004), and coaches may impact this match due to their influence on shaping motivational sport climates. For example, exhaustion and reduced accomplishment burnout dimensions are negatively associated with a mastery climate, while sport devaluation is positively related to a performance climate (Lemyre et al., 2008). Vitali et al. (2015) recently examined motivational climate and burnout in youth athletes and found that a mastery climate was negatively correlated with burnout dimensions while a performance climate was positively related to burnout. Finally, longitudinal research has shown a positive association between coach-created ego climates and burnout (Ntoumanis et al., 2012), suggesting that athletes who perceive the coach-created climate as more performance-involved and less mastery-involved may be at greater burnout risk.

A useful framework for examining youth sport burnout is the Developmental Model of Sport Participation (DMSP; Côté \& Fraser-Thomas, 2007), as it describes various potential youth athlete experiences. Specifically, the DMSP focuses on youths' (ages 7-18) sport experiences and contains three potential tracks: (1) attainment of elite performance through early sport specialization, (2) attainment of elite performance through multi-sport sampling, and (3) eventual recreational sport participation through multi-sport sampling (Côté \& Fraser-Thomas, 2007). The tracks contain various development phases after entry into sport with multi-sport participation referred to as "sampling". The tracks also posit different proportions 
of deliberate play and deliberate practice activities are evident throughout a youth athlete's sport development. Deliberate play activities often involve little adult oversight, are loosely structured, and organized by athletes themselves (e.g., street hockey); they develop sport skills but emphasize intrinsic motivation (Côté, 1999). Deliberate practice activities usually involve a coach's presence, structured sport-specific drills and conditioning, and are focused on future athletic improvement (Ericsson et al., 1993). A noted deliberate practice constraint is that it is less enjoyable and requires greater cognitive/physical effort and commitment (Ericsson et al. 1993), and youth who experience earlier involvement in less enjoyable sport activities have less intrinsic motivation (Law et al., 2007), increasing burnout risk.

The DMSP elite performancethrough-sampling track describes progression through three phases: sampling (ages 6-12), specializing (ages 13-15), and investment years (ages 16+), with a gradual tapering of sport emphasis across phases (Côté et al., 2007). In the sampling years, youth engage in various sports, focused primarily on skill development and deliberate play. In the specializing years, deliberate play and deliberate practice are more balanced in fewer sports, one of which is the athlete's eventual focal sport. Finally, the investment years are marked by extensive deliberate practice in one's focal sport. The early specialization track, however, is defined by direct entry into intensive early single-sport participation with greater adult involvement, competitiveness, deliberate practice, and training volumes.

Because burnout is thought to be linked to early specialization (Fraser-Thomas et al., 2005; Harris \& Watson, 2014) and specialized sport environments appear linked to less self-determined motivation (Law et al., 2007; Wall \& Côté, 2007), youth who specialize early may display motivational profiles predictive of burnout more than multi-sport athletes. In addition, since coach-created motivational climates influence motivation and burnout (e.g., Lemyre et al., 2008) motivational climate may also explain burnout. Although previous research has examined connections between sport motivation and burnout, as well as between motivational climate and burnout, these associations have not been investigated directly within the DMSP framework. Furthermore, previous research comparing specializers and samplers has focused almost exclusively on elite youth athletes' experiences (e.g., Bridge \& Toms, 2013; Law et al., 2007; Strachan et al., 2009), and the experiences of specializers and samplers in more typical (non-elite) amateur athlete populations is unknown, yet understanding non-elite athlete experiences bears importance as they represent a much greater proportion of all youth athletes.

Therefore, the purpose of this study was to examine the relationship between athletes' sport motivations, perceived motivational climate and burnout by comparing these relationships in former high school athletes matching either the DMSP early specialization or early sam- 
pling track. Specifically, recall of young adults' experiences who participated in a single sport from a young age (before age 12) and continued that same sport throughout high school (specializers) was compared with young adults' experiences who participated in multiple sports (samplers) at a young age (before age 12) and continued only one of those sports throughout high school on their sport motivations, motivational climate perceptions, and athlete burnout perceptions. Specifically, because previous research has posited that youth athletes in specialized environments display less self-determined motivation (Law et al., 2007; Wall \& Côté, 2007), perceive greater ego-involving climates (Vitali et al., 2015), and display higher burnout levels compared to multi-sport athletes (Fraser-Thomas et al, 2008; Strachan et al., 2009; Wall \& Côté, 2007), it was hypothesized that specializers would display less self-determined sport motivation, higher ego-involved motivational climate perceptions, and greater athletic burnout compared to samplers. In addition, it was also hypothesized that the early specialization track, amotivation and extrinsic motivations (external, identified regulation), and perceived ego-involving climate would positively predict participants' burnout perceptions from their youth sport experience.

\section{Method}

\section{Participants and Procedures}

A sample of 156 students (55 males, 101 females; $M$ age $=19.75, S D=1.89)$ who participated in organized youth sport and one high school sport were surveyed through general education courses at a mid-size Midwestern university. Forty-three participants $(28 \%)$ were single-sport specializers while $118(72 \%)$ were samplers. In regard to their current status in their high school sport, 46 (29.5 $\%$ ) were currently competitive in their sport, $53(34 \%)$ were recreational participants, and 57 (36.5\%) no longer participated in their sport. Those no longer active in their sport provided a reason for non-participation and the most common reasons were "focus on school" $(n$ $=13 ; 22.8 \%)$, "lack of time" $(n=12$; $21.1 \%)$, "injury" ( $n=7 ; 12.3 \%)$, and "lack of enjoyment" $(n=6 ; 10.5 \%)$. Upon institutional review board approval and instructors' permission, volunteers who met inclusion criteria completed a survey packet. All surveys were directly administered, with participants signing informed consent before completing surveys and names were omitted, maintaining anonymity.

\section{Measures}

Participants completed surveys containing demographic information and selected whether they met the criteria describing either the DMSP specialization or sampling track. In addition, participants were assessed on the following constructs.

Motivational Climate. The Motivational Climate Scale for Youth Sport (MCSYS; Smith et al., 2008) measures perceived motivational climate in youth sport and contains 12 statements related to coach-created motivational climate on a 1 (Not at all true) to 5 (Very true) Likert-type 
scale. Six items are linked to a task-involving (mastery) climate while six items are related to an ego-involving (performance) climate. Sample items include "The coach pays most attention to the best players" (ego-involving), and "The coach says that all of us are important to the team's success" (task-involving). Because surveys assessed recall, items were revised to the past tense and participants were asked to reflect on their high school sport. Smith et al. (2008) reported acceptable internal consistency ranging from $a=.74$ to .84 for the mastery and ego scale. Internal consistency scores in the current study were $a=.90$ for the mastery scale and $a=.75$ for the ego scale.

Sport Motivation. The Sport Motivation Scale-II (SMS-II; Pelletier et al., 2013) assesses six types of motivation within the SDT framework including intrinsic regulation, integrated regulation, identified regulation, introjected regulation, external regulation, and non-regulation, and contains 18 items (three per subscale) assessed on a seven-point (1 = does not correspond at all to $7=$ corresponds exactly) Likert-type scale. Items were revised to the past tense and asked about motivations for participants' high school sport participation. Pelletier et al. (2013) reported adequate internal consistency (.73 to .86) for the SMS-II subscales, and alpha coefficients for SMS-II subscales in this study ranged from $a=.72$ to .77 , except for introjected regulation $(a=.69)$.

Burnout. The Athlete Burnout Questionnaire (ABQ; Raedeke \& Smith, 2001) is a 15 -item inventory with that assesses the burnout dimensions of emotional/ physical exhaustion, reduced sense of accomplishment, and sport devaluation. Because data assessed recall, participants were instructed to recall how they felt about their high school sport participation on the dimensions of emotional/ physical exhaustion (e.g., I felt overly tired from my sport participation), reduced sense of sport accomplishment (e.g., I was not performing up to my ability in my sport), and sport devaluation (e.g., I didn't care as much about my sport performance as much as I used to). Participants responded on a five-point (1 $=$ almost never to $5=$ almost always) Likerttype scale, with higher scores reflecting greater burnout. The ABQ has shown acceptable internal consistencies above .80 for all subscales (Raedeke \& Smith, 2001) and also showed acceptable internal consistencies ( $a=.79$ to .91$)$ in this study.

\section{Data Analysis}

Data analysis was performed with SPSS (Version 23.0) for Windows. Descriptive statistics were computed to examine MCSYS, SMS-II, and ABQ subscale scores for the entire sample and by sport track. Pearson product moment correlations were conducted to examine associations among sport motivations, motivational climate, and burnout dimensions. A chi-square analysis was performed to compare whether specializers and samplers differed on their current self-reported participation in their high school sport (competitive, recreational, or not participating). Three separate 
one-way MANOVAs were conducted to examine DMSP track (specializer/sampler) differences on sport motivation, motivational climate, and athlete burnout. Finally, separate stepwise multiple regressions were performed to examine whether burnout dimensions (ABQ) could be predicted by DMSP track, sport motivations and motivational climate.

\section{Results}

Results of a MANOVA on DMSP track differences on burnout dimensions were not significant (Wilk's $\lambda(4,151)=$ $.990, p>.05)$, indicating neither ABQ dimensions nor global burnout were influ- enced by DMSP track (specializer/sampler). In addition, results of a separate MANOVA examining the difference of DMSP track on sport motivations were nonsignificant (Wilk's $\lambda(6,149)=.968, p$ $>$.05), indicating that sport motivations of former high school athletes were not influenced by DMSP track. Finally, a separate MANOVA examining the difference of DMSP track on perceptions of coach-created motivational climate were also nonsignificant (Wilk's $\lambda(2,153)$ $=.981, p>.05)$, indicating that neither perceptions of ego-involving or task-involving climates differed by DMSP track. Means and standard deviations

Table 1

Means and standard deviations for sport motivations, motivational climate perceptions, and athletic burnout across DMSP track

\begin{tabular}{lcccc}
\hline & \multicolumn{2}{c}{ Specializers } & $(n=43)$ & \multicolumn{2}{c}{ Samplers $(n=113)$} \\
SMS-II & $M$ & $S D$ & $M$ & $S D$ \\
Intrinsic Regulation & & 3.82 & 17.40 & 3.38 \\
Integrated Regulation & 16.53 & 3.96 & 16.12 & 4.01 \\
Identified Regulation & 15.00 & 3.68 & 17.66 & 3.48 \\
Introjected Regulation & 16.40 & 3.99 & 12.55 & 3.99 \\
External Regulation & 12.44 & 5.04 & 9.89 & 4.79 \\
Non-Regulation & 9.65 & 4.89 & 6.10 & 3.61 \\
MCSYS & 7.00 & & & 5.40 \\
Mastery-Involved Climate & 22.56 & 5.40 & 24.18 & 5.44 \\
Ego-Involved Climate & 17.49 & 5.13 & 17.28 & .77 \\
ABQ & & & & .98 \\
Red. Sense of Accomp. & 2.02 & .78 & 2.00 & .92 \\
Emotional/Physical Exhaust. & 2.39 & .85 & 2.34 & .92 \\
Sport Devaluation & 2.07 & 1.02 & 2.14 & \\
Global Burnout & 2.28 & .87 & & \\
\hline
\end{tabular}




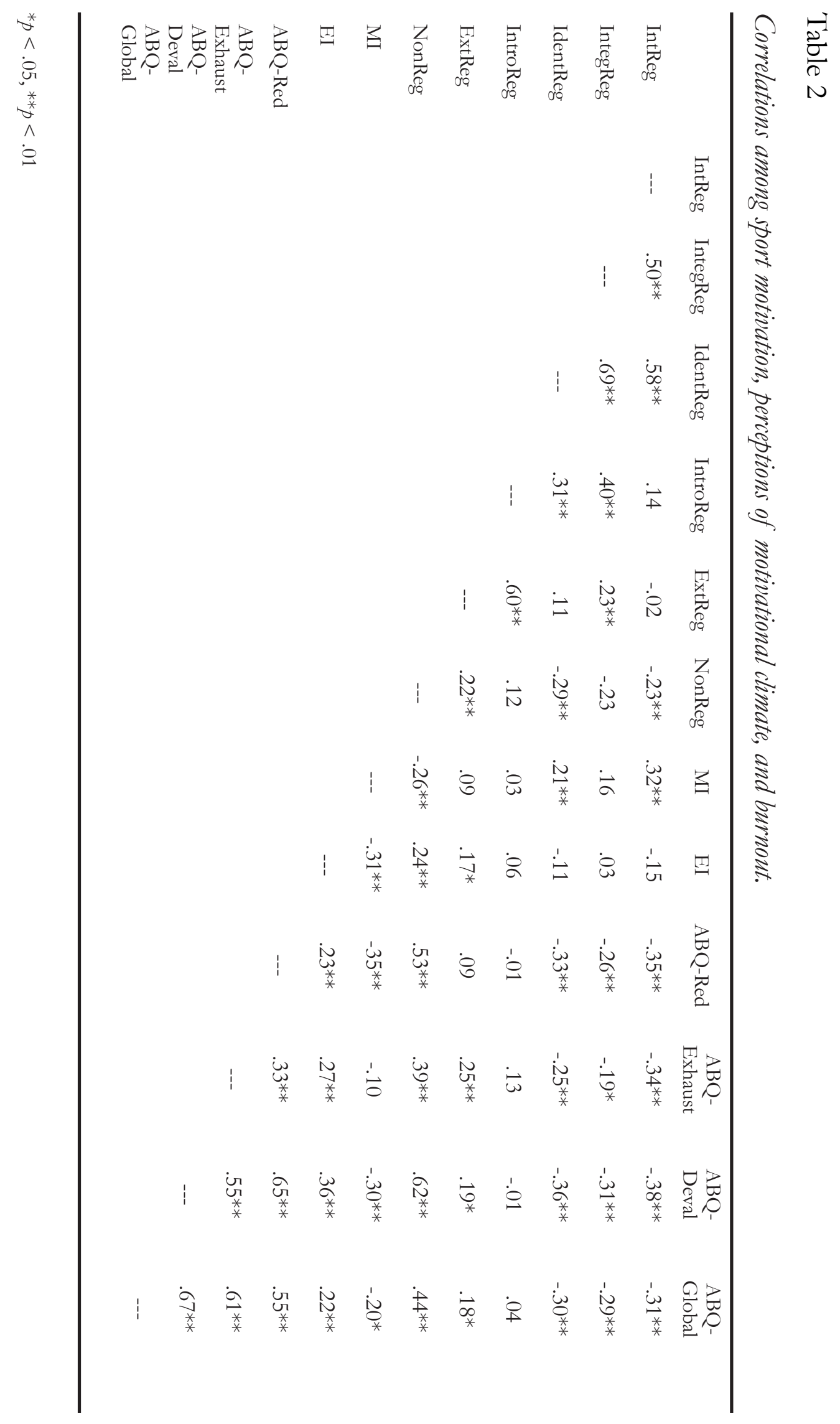

Journal of Amateur Sport Volume Seven, Issue One Russell, 20218 
(by DMSP track) for sport motivation, motivational climate, and burnout are displayed in Table 1. Chi-square results examining whether current participation status (competitive, recreational, not participating) differed by DMSP track found no significant relationship $\left(X^{2}(2)=5.44\right.$, $p>.05)$, indicating participants' current participation in their high school sport did not differ by DMSP track.

Four stepwise multiple regression analyses were performed using global burnout and $A B Q$ dimensions as criterion variables and DMSP track, sport motivations, and motivational climate dimensions as predictors. Correlations among sport motivations, motivational climate, and burnout dimensions are shown in Table 2. Results of regression analyses are presented in Table 3 and are summarized in the following sections.

Global Burnout. For the first regression analysis with global burnout as the criterion, SMS non-regulation (amotivation) entered the regression at step 1 as a significant predictor $\left(R=.44, R^{2}=.19, p\right.$ $<.00)$. Examination of the beta weight $(\beta=.44)$ indicated that amotivation was positively related to global burnout. At step 2, the addition of intrinsic regulation resulted in a significant increase in variance explained $\left(R^{2}\right.$ change $=.04, p<$ $.01)$. The beta weight $(\beta=-.22, p<.01)$ was negative, indicating that low intrinsic regulation was predictive of higher global burnout. No other predictors entered into the equation at step 3 of the analysis $(p>.05)$.

Emotional/Physical Exhaustion. Results revealed a significant effect for amotiva- tion at step $1\left(\mathrm{R}=.39, \mathrm{R}^{2}=.15, p<.00\right)$. The beta weight $(\beta=.39)$ indicated that higher levels of amotivation were predictive of higher exhaustion. At step 2, the addition of intrinsic regulation resulted in a significant increase in variance explained $\left(R^{2}\right.$ change $\left.=.07, p<.01\right)$. The beta weight $(\beta=-.27, p<.01)$ was negative, indicating that lower levels of intrinsic regulation were predictive of higher exhaustion. At step 3, external regulation also added a significant increase in variance explained $\left(R^{2}\right.$ change $=.03, p<$ $.05)$. The beta weight $(\beta=.18, p<.05)$ was positive, indicating that higher levels of external regulation were predictive of greater exhaustion. Finally, at step 4, the addition of performance motivational climate revealed a significant increase in variance explained $\left(R^{2}\right.$ change $=.02, p<$ $.05)$. The beta weight $(\beta=.15, p<.05)$ indicated that higher levels of perceived performance climate were predictive of exhaustion. No other predictors entered into the equation at step 5 of the analysis $(p>.05)$.

Reduced Sense of Accomplishment. Results revealed a significant effect at step 1 for amotivation $\left(R=.53, R^{2}=.28, p<\right.$ $.00)$. The beta weight $(\beta=.53)$ indicated that amotivation was predictive of greater sense of reduced accomplishment. At step 2, intrinsic regulation added a significant increase in variance explained $\left(R^{2}\right.$ change $=.06, p<.00)$. The beta weight $(\beta=-.24, p<.01)$ indicated that intrinsic regulation was negatively related to reduced sense of accomplishment. Finally, at step 3, the addition of mastery motivational climate revealed a significant 


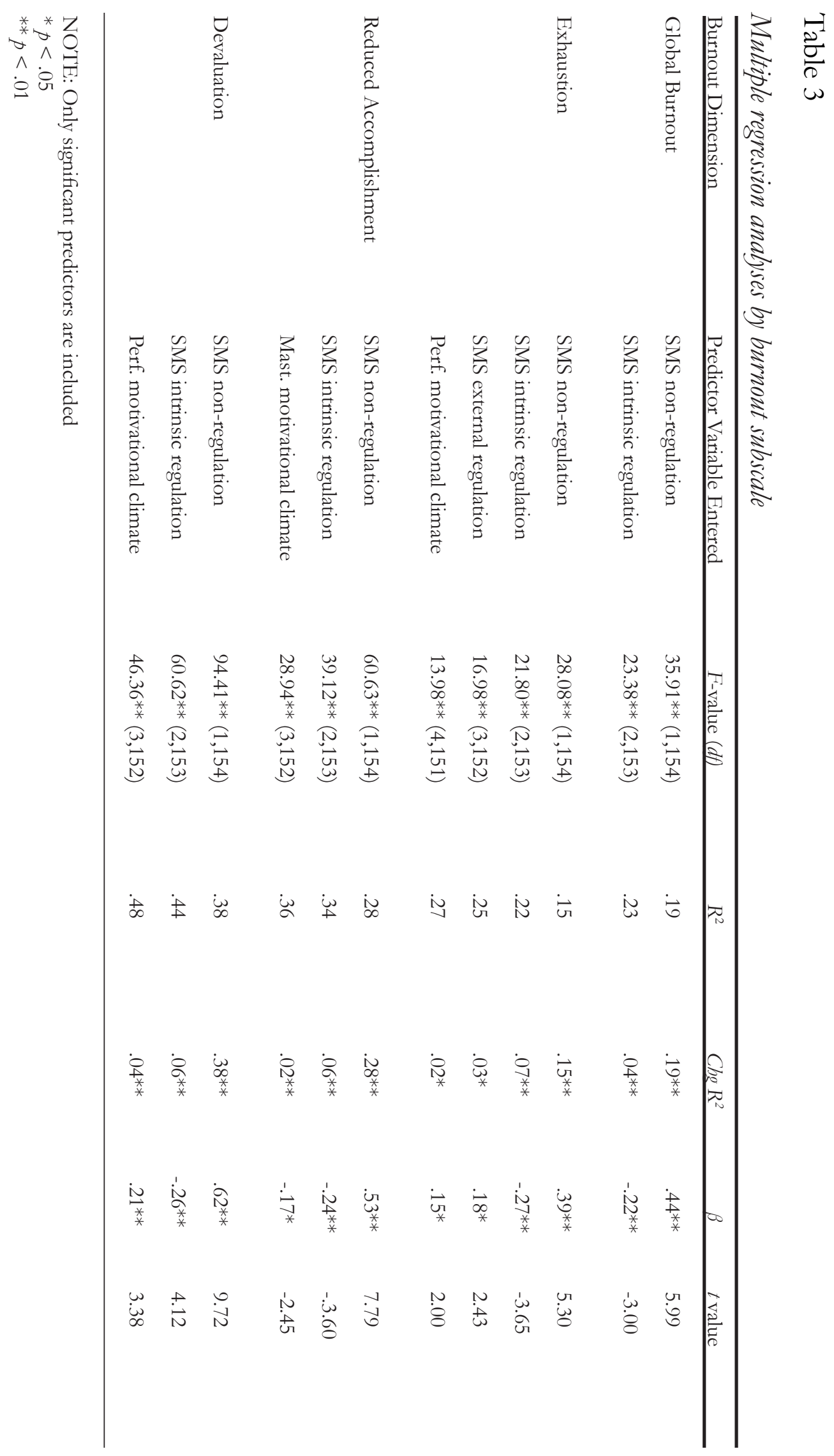

Journal of Amateur Sport Volume Seven, Issue One Russell, 202110 
increase in variance explained $\left(R^{2}\right.$ change $=.02, p<.05)$. The beta weight $(\beta=$ $-.17, p<.05)$ was negative, indicating that perceived mastery motivational climate was negatively related to reduced sense of accomplishment. No other predictors entered into the equation at step 4 of the analysis $(\phi>.05)$.

Sport Devaluation. Results revealed a significant effect at step 1 for amotivation $\left(R=.62, R^{2}=.38, p<.00\right)$. The beta weight $(\beta=.62)$ indicated that amotivation predicted athletes' sport devaluation. At step 2, the addition of intrinsic regulation resulted in a significant increase in variance explained $\left(R^{2}\right.$ change $=.06, p<$ $.00)$. The beta weight $(\beta=-.26, p<.01)$ indicated that intrinsic regulation was negatively related to athletes' perceived sport devaluation. Finally, at step 3, the addition of performance motivational climate revealed a significant increase in variance explained $\left(R^{2}\right.$ change $=.04, p<$ $.00)$. The beta weight $(\beta=.21, p<.00)$ indicated that a perceived performance climate was positively related to sport devaluation. No other predictor variables entered into the equation at step 4 of the analysis $(p>.05)$.

\section{Discussion}

This study examined former high school athletes' sport motivations, motivational climate perceptions, and athlete burnout across DMSP track, and results indicated that none of these variables differed by sport track. Amotivation was a significant predictor of all burnout dimensions, supporting that amotivation is most strongly associated with burn- out (Cresswell \& Eklund, 2005a, 2005b; Raedeke \& Smith, 2009). Intrinsic motivation was a negative predictor of burnout, supporting that burnout is negatively predicted by self-determined motivation (Li et al., 2013; Lonsdale et al., 2009). Finally, a mastery climate was negatively associated with reduced sense of accomplishment while a performance climate was positively associated with exhaustion and sport devaluation, supporting previous findings on motivational climate and burnout (Lemyre et al., 2008; Vitali et al., 2015).

Given that sport motivations, motivational climate perceptions, and burnout did not differ by DMSP track, results support that specializers and samplers may be similar in their sport experiences (Strachan et al., 2009), particularly in non-elite youth settings, which have been largely ignored in youth sport research. Strachan et al. posited that similarities could be because youth sport fosters positive outcomes regardless of track. They found specializers higher in exhaustion, yet their specializers averaged considerable weekly training hours $(M=$ 19.2) and were national-level, individual-sport athletes (e.g., swimming) known for earlier intensive training (Baker et al., 2005). Although speculative, former specializers in this sample may not have invested similar training volumes, thus contributing to non-significant differences.

The lack of DMSP track differences may also have been because, while respondents were categorized into tracks based on their sport history prior to 
age 12 , specific information on training habits and sport development milestones (e.g., first competitive tournament) was not measured. Fraser-Thomas et al., (2008), for example, retrospectively compared youth sport dropout and sport persistence by examining such factors and found that dropouts were involved in fewer extracurricular activities, less deliberate play, and reached sport milestones earlier than still-engaged athletes. In addition, research has noted training volume and intensity may influence burnout (Gustafsson, Kenttä, Hassmén, \& Lundqvist, 2007). Thus, more specific training information on youth athletes' experiences (e.g., practice conditions, deliberate practice volumes, recovery time) needs to be included for more robust DMSP track comparisons. Lack of DMSP track differences may also have been due to samplers' sport perceptions as they transitioned from sampling (ages 6-12) to investment years (age 16+). The DMSP transitional specializing stage (ages 13-15; Côté et al., 2007) is one in which youth develop in one or two sports, where skill acquisition is balanced with participation and fun (Côté \& Fraser-Thomas, 2007). Athletes in this stage often perceive deliberate practice more positively because it accentuates greater personal challenge and subsequent confidence, which fosters persistence (Macphil $\&$ Kirk, 2006). If this process occurred with current samplers, their overall sport experiences could have been similar to specializers. Also of note, lack of significant chi-square results on current sport participation across DMSP track refutes the notion that early specialization is systematically related to progression to higher levels (i.e., collegiate) of sport (Hodges \& Starkes, 1996).

Current results also support the utility of the SDT framework in that amotivation was most related to burnout (Cresswell \& Eklund, 2005a, 2005b; Raedeke \& Smith, 2009), as it was a significant predictor of all burnout dimensions. Intrinsic motivation was also a significant negative predictor of exhaustion and sport devaluation. As such, this finding supports that burnout is negatively correlated with intrinsic motivation (Holmberg \& Sheridan, 2013; Li et al., 2013; Raedeke \& Smith, 2001). This also indirectly supports the Sport Commitment Model (Scanlan et al., 2009) which identifies antecedents to athletes' sport commitment level. According to Scanlan et al., factors such as an athlete's sport enjoyment, valuable opportunities, attractive sport alternatives, personal investments, and social support can all determine sport commitment. Yet, sport enjoyment is noted as the most critical variable, in that athletes will not remain committed to their sport if they do not find enjoyment (intrinsic motivation) in their continued involvement.

Regarding motivational climate and burnout, results support that former youth athletes' motivational climate perceptions also influenced burnout perceptions. A mastery climate was a significant negative predictor of reduced sense of accomplishment, and a performance climate was predictive of exhaustion and sport devaluation. As such, these findings reinforce that a mastery 
climate may lower burnout risk, whereas a performance climate may increase it (Vitali et al., 2015). This makes sense, as a coach's emphasis on outperforming others epitomizes a performance climate, and placing excessive prominence on interpersonal comparisons and winning may impede feelings of personal development and success, leading athletes to devalue effort, fostering frustration, and emotional exhaustion. Because recall was from participants' entire high school sport experience, results support that coach-created performance climates predict burnout, especially over extended periods in which athletes participate in the same coach-created motivational climate (Ntoumanis et al., 2012). Such findings support that motivational climates emphasizing outcome and normative comparisons while minimizing improvement may be linked to perceptions of pressure and energy depletion (Lemyre et al., 2008; Smith et al., 2010).

\section{Limitations and Future Research}

The current findings should be considered in light of several limitations. First, since data was from recall of youth sport experiences, limitations to recall accuracy are acknowledged. However, this concern is somewhat attenuated in that research (e.g., Bridge \& Toms, 2013) suggests high recall reliability for recurrent and prominent lifetime activities like youth sport, and recall from similar sport developmental periods has been shown to be reliable (Côté et al.,2005). Nevertheless, longitudinal studies (e.g., Isoard-Gauthier et al., 2016) are needed where youth are followed across DMSP tracks into adolescence to understand how factors like motivational climate, training habits, and sport motivations influence burnout over time.

Second, a noted sport burnout research limitation (e.g., Gustafsson et al., 2011) has been that research has used athletes low in burnout, which may have occurred in this sample. Raedeke \& Smith (2009) suggest when interpreting burnout severity, the bottom third of normative ABQ subscale scores can be considered low in burnout. Current participants' ABQ means were below the bottom third cutoff for exhaustion ( $M$ $=2.40$ ), at the bottom third cutoff for reduced sense of accomplishment $(M=$ 2.00) and slightly above the bottom third cutoff $(M=1.60)$ for sport devaluation (specializers $M=2.07$; samplers $M=$ 1.93), reflecting fairly low burnout. This is further supported in that respondents persisted in their individual sport throughout high school. Thus, future research should target youth athletes experiencing greater burnout. Caution is also warranted in data interpretation as the variance explained by motivational climates was small $\left(R^{2}=2-4 \%\right)$ and the alpha for introjected regulation (SMS-II) was .69, just below the generally accepted $.70 \mathrm{lev}-$ el (Nunnally \& Bernstein, 1994).

In addition, the sample size was small $(N=156)$ as was the number of specializers $(n=43)$, which may have contributed to non-significant DMSP track differences. The low number of specializers may owe to the geographic location of the university where data 
were collected, as many participants may have come from smaller, rural communities where athletes are afforded greater multi-sport opportunities (Balish \& Côté, 2011) and may be less likely to specialize early in one sport compared to athletes from larger communities. In fact, evidence suggests youth sport participation in smaller communities may be beneficial to athlete development, due to greater unstructured deliberate play opportunities, multi-sport participation, and sport development social support (Turnnidge et al., 2014). Although this explanation of fewer specializers is speculative, scholars should compare samplers and specializers across their city of sport development to determine the impact of this factor within the DMSP.

The retrospective timeframe (entire high school sport experience) may also have prevented insights into burnout across DMSP track. First, this timeframe may have masked temporal changes in participants' burnout across the high school time period. Qualitative research notes that burnout shows variability in its evolution (e.g., Gustafsson, Kenttä, Hassmén, Lundqvist, \& Durand-Bush, 2007), yet the current design precluded insights into how sequencing of burnout perceptions may develop. Second, according to the DMSP, by the time samplers transition into their investment (high school) years, their sport perceptions, coach relationship, and peer interactions may be more similar to early specializers, compared to earlier phases of the DMSP sampling track (Côté \& Fraser-Thomas, 2007). For example, high school coaches might display more similarities in coaching behaviors and athlete interactions by engaging in more autonomy-supportive behaviors compared to coaches at earlier youth sport levels. Thus, current samplers may have been well into their DMSP investment years and similar to specializers in their coach-athlete relationship and training volumes. Future research should compare DMSP tracks at younger ages (ages 10-15), when athletes may have more disparate experiences. Finally, participants who may have experienced a coaching change during their high school sport could have experienced different motivational climates during their retrospective timeframe.

It also must be acknowledged that the distinction between elite and non-elite youth sport settings is an important one. Qualitative research (e.g., Gustafsson, Kenttä, Hassmén, Lundqvist, \& Durand-Bush, 2007, Gustafsson et al., 2008) indicates that early sport success may hasten burnout. Talented young athletes garner increased adult attention (Stambulova, 2009), which may increase stress, expectations, and exhaustion levels, all of which may precede burnout (Gustafsson et al., 2011). Yet in non-elite amateur settings, specializers may not experience these factors as intensely, thus may not experience resultant burnout to the same degree as elite youth athletes. This is speculative, yet provides further rationale for comparing specializers' and samplers' experiences in non-elite youth sport settings. Finally, while this design compared respondents' recall of motivational climate, sport motivations, and burnout 
across DMSP track, it did not assess practice structures, training habits, or volume/frequency of deliberate play and deliberate practice activities (like Strachan et al., 2009). The DMSP notes that early specialization involves extensive deliberate practice (Côté et al., 2007), which may not have occurred with specializers in this sample. In short, participants were simply categorized according to their self-reported DMSP track; however, more detailed sport history information (e.g., average weekly hours invested in their sport) was not obtained, limiting insights into potential track differences.

Future research comparing athletes across DMSP tracks should also examine social constructs for their burnout impact. Pacewicz et al. (2019) recently noted that negative social interactions are associated with athlete burnout and called for researchers to examine how social support from key individuals (e.g., teammates) might influence burnout development. Chronic negative social interactions could erode perceptions of competence, thereby reducing intrinsic motivation and increasing burnout vulnerability. Thus, research should assess social support to ascertain if this construct influences burnout across DMSP tracks.

Despite the aforementioned limitations, these findings support that former high school athletes in the DMSP sampling and specialization tracks appear similar in sport motivations, motivational climate perceptions, and burnout, while supporting SDT for examining youth sport burnout. Future research should integrate assessment of social support and directly compare these DMSP tracks in a longitudinal design to examine how temporal changes in training habits, deliberate play/practice patterns, sport motivations, social support, and perceptions of motivational climate may influence progression of youth athlete burnout.

\section{References}

Ames, C. (1992). Classrooms: Goals, structures, and student motivation. Journal of Educational Psychology, 84, 261-271.

Baker, J. (2003). Early specialization in youth sport: A requirement for adult expertise? High Ability Studies, 14, 8594.

Baker, J., Côté, J., \& Deakin, J. (2005). Expertise in ultra-endurance triathletes early sport involvement, training structure, and theory of deliberate practice. Journal of Applied Sport Psychology, 17, 64-78.

Balish, S., \& Côté, J. (2011). The social and ecological parameters of a successful sporting community. Journal of Sport \& Exercise Psychology, 33, S129.

Bridge, M. W., \& Toms, M. R. (2013). The specialising or sampling debate: A retrospective analysis of adolescent sports participation in the UK. Journal of Sport Sciences, 31, 87-96.

Côté, J. (1999). The influence of the family in the development of talent in sports. The Sport Psychologist, 13, 395417.

Côté, J., Baker, J., \& Abernathy, B. (2007). Practice and play in the development of sport expertise. In R. C. Eklund \& G. Tenenbaum, (Eds.) Handbook of sport psychology (pp. 184-202). John Wiley \& Sons. 
Côté, J., Ericsson, K. A., \& Law, M. P. (2005). Tracing the development of athletes using retrospective interview methods: A proposed interview and validation procedure for reported information. Journal of Applied Sport Psychology, 17(1), 1-19.

Côté, J., \& Fraser-Thomas, J. (2007). Youth involvement in sport. In P. Crocker (Ed.), Sport psychology: A Canadian perspective. (pp. 270-298). Pearson.

Cresswell, S. L., \& Eklund, R. C. (2005a). Changes in athlete burnout and motivation over a 12 -week league tournament. Medicine and Science in Sports and Exercise, 37, 1956-1966.

Cresswell, S. L., \& Eklund, R. C. (2005b). Motivation and burnout among top amateur rugby players. Medicine and Science in Sports and Exercise, 37, 469477.

Deci, E., \& Ryan, R. (1985). Intrinsic motivation and self-determination in human behavior. Plenum.

Deci, E. L., \& Ryan, R. M. (2000). The "what" and "why" of goal pursuits: Human needs and the self-determination theory. Psychological Inquiry, 11, 227-268.

Duda, J. L., \& Balaguer, I. (2007). The coach-created motivational climate. In D. Lavalee \& S. Jowett (Eds.), Social psychology of sport (pp. 117-130). Human Kinetics.

Ericsson, K. A., Krampe, R. T., \& TeschRömer, C. (1993). The role of deliberate practice in the acquisition of expert performance. Psychological Review, 100, 363-406.
Fraser-Thomas, J., Côté, J., Deakin, J. (2008). Examining adolescent sport dropout and prolonged engagement from a developmental perspective. Journal of Applied Sport Psychology, 20, 318-333.

Fraser-Thomas, J., Côté, J., Deakin, J. (2005). Youth sport programs: An avenue to foster positive youth development. Physical Education and Sport Pedagogy, 10(1), 19-40.

Gould, D. (2010). Early sport specialization: A psychological perspective. Journal of Physical Education, Recreation, and Dance, 81, 33-37.

Gould, D., \& Diffenbach, K. (2002). Overtraining, underrecovery, and burnout in sport. In M. Kellmann (Ed.), Enhancing recovery: Preventing underperformance in athletes (pp. 25-35). Human Kinetics.

Gould, D., Udry, E., Tuffey, S., \& Loehr, J. (1996). Burnout in competitive junior tennis players: II Qualitative Analysis. The Sport Psychologist, 10, 341-366.

Gustafsson, H., Hassmén, P., Kenttä, G., \& Johansson, M. (2008). A qualitative analysis of burnout in elite Swedish athletes. Psychology of Sport \& Exercise, 9, 800-816.

Gustafsson, H., Kenttä, G., \& Hassmén, P. (2011). Athlete burnout: An integrated model and future research directions. International Review of Sport and Exercise Psychology, 4(1), 3-24.

Gustafsson, H., Kenttä, G., Hassmén, P., \& Lundqvist, C. (2007). Prevalence of burnout in competitive adolescent athletes. The Sport Psychologist, 21, 2137. 
Gustafsson, H., Kenttä, G., Hassmén, P., Lundqvist, C., \& Durand-Bush, N. (2007). The process of burnout: A multiple case study of three elite endurance athletes. International Journal of Sport Psychology, 38, 388-416.

Hansen, D. M., Larson, R. W., \& Dworkin, J. B. (2003). What adolescents learn in organized youth sport activities: A survey of self-reported developmental experiences. Journal of Research on Adolescence, 13, 25-55.

Harris, B. S., \& Watson, J. C. (2011). Assessing youth sport burnout: A selfdetermination and identity development perspective. Journal of Clinical Sport Psychology, 5, 117-133.

Harris, B. S., \& Watson, J. C. (2014). Developmental considerations in youth athlete burnout: A model for youth sport participants. Journal of Clinical Sport Psychology, 8, 1-18.

Hodges, N. J., \& Starkes, J. L. (1996). Wrestling with the nature of expertise: A sport specific test of Ericsson, Krampe, and Tesch-Römer's (1993) theory of deliberate practice. International Journal of Sport Psychology, 27, 400-424.

Holmberg, P. M., \& Sheridan, D. A. (2013). Self-determined motivation as a predictor of burnout among college athletes. The Sport Psychologist, 27, 177-187.

Isoard-Gauthier, S., Guillet-Descas, E., \& Gustafsson, H. (2016). Athlete burnout and the risk of dropout among elite young handball players. The Sport Psychologist, 30(2), 123-130.
Jayanthi, N. A., LaBella, C. R., Fischer, D., Pasulka, J., \& Dugas, L. R. (2015). Sports- specialized intensive training and the risk of injury on youth athletes: A clinical case-control study. The American Journal of Sports Medicine, 43(3), 794-801.

Law, M. P., Côté, J., \& Ericsson, K. A. (2007). Characteristics of expert development in rhythmic gymnastics: A retrospective study. International Journal of Sport \& Exercise Psychology, 5, 82-103.

Lemyre, P. N., Hall, H. K., \& Roberts, G. C. (2008). A social cognitive approach to burnout in elite athletes. Scandinavian Journal of Medicine \& Science in Sports, 18, 221-234.

Li, C., Wang, C. K., Pyun, D. Y., \& Kee, Y. H. (2013). Burnout and its relations with basic psychological needs and motivation among athletes: A systematic review and meta-analysis. Psychology of Sport and Exercise, 14, 692700.

Lonsdale, C., Hodge, K., \& Rose, E. (2009). Athlete burnout in elite sport: A self-determination perspective. Journal of Sport Sciences, 27(8), 785795.

Macphail, A., \& Kirk, D. (2006). Young people's socialization into sport: Experiencing the specializing phase. Leisure Studies, 25, 57-74.

Moesch, K., Elbe, A. M., Hauge, T., \& Wikman, J. M. (2011). Late specialization: The key to success in centimeters, grams, or seconds (cgs) sports. Scandinavian Journal of Medicine and Science in Sports, 21, 282-290. 
Ntoumanis, N., \& Biddle, S. J. H. (1999). A review of motivational climate in physical activity. Journal of Sport Sciences, 17, 643-665.

Ntoumanis, N., Taylor, I. M., \& Thorgersen-Ntoumani, C. (2012). A longitudinal examination of coach and peer motivational climates in youth sport: Implications for moral attitudes, well-being, and behavioral investment. Developmental Psychology, 48(1), 213-223.

Nunnally, J. C., \& Bernstein, L. H. (1994). Psychometric theory. ( $3^{\text {rd }}$ ed.). Mc-

Graw-Hill.

Pacewicz, C. E., Mellano, K. T., \& Smith, A. L. (2019). A meta-analytic review of the relationship between social constructs and athlete burnout. Psychology of Sport \& Exercise, 43, 155164.

Pelletier, L., Rocchi, M., Vallerand, R., Deci, E., \& Ryan, R. (2013). Validation of the revised Sport Motivation Scale (SMS-II). Psychology of Sport \& Exercise, 14, 329-341.

Raedeke, T. D., \& Smith, A. L. (2001). Development and preliminary validation of an athlete burnout measure. Journal of Sport \& Exercise Psychology, 23, 281-306.

Raedeke, T. D., \& Smith, A. L. (2004). Coping resources and athlete burnout: An examination of stress mediated and moderation hypotheses. Journal of Sport \& Exercise Psychology, 26, 525-541.

Raedeke, T.D., \& Smith, A.L. (2009). The athlete burnout questionnaire manual. Fit Publishing.
Reinboth, M., \& Duda, J. L. (2004). The motivational climate, perceived ability, and athletes' psychological and physical well-being. The Sport Psychologist, 18, 237-251.

Ryan, R., \& Deci, E. L. (2000). The darker and brighter sides of human existence: Basic psychological needs as a unifying concept. Psychological Inquiry, 11, 319-338.

Scanlan, T. K., Russell, D. G., Magyar, T. M., \& Scanlan, L. A. (2009). Project on elite athlete commitment (PEAK): III. An examination of the external validity across gender, and the expansion and clarification of the sport commitment model. Journal of Sport \& Exercise Psychology, 31(6), 685-705.

Smith, R. E., Cumming, S. P., \& Smoll, F. L. (2008). Development and validation of the Motivational Climate Scale for Youth Sports. Journal of Applied Sport Psychology, 20, 116-136.

Smith, A. L., Gustafsson, H., \& Hassmén, P. (2010). Peer motivational climate and burnout perceptions in adolescent athletes. Psychology of Sport \& Exercise, 11, 453-460.

Stambulova, N. (2009). Talent development in sport: Career transitions perspectives. In E. Tsung-Min Hung, \& R. Lidor (Eds.), Psychology of excellence (pp. 63-73). ISSP.

Strachan, L., Côté, J., \& Deakin, J. (2009). "Specializers" versus "samplers" in youth sport: Comparing experiences and outcomes. The Sport Psychologist, 23, 77-92. 
Turnnidge, J., Hancock, D. J., \& Côté, J. (2014). The influence of birth date and place of development on youth sport participation. Scandinavian Journal of Medicine \& Science in Sports, 24, 461-468.

Vitali, F., Bortoli, L., Bertinato, L., Robazza, L., \& Schena, F. (2015). Motivational climate, resilience, and burnout in youth sport. Sport Science and Health, 11, 103-108.

Wall, M., \& Côté, J. (2007). Developmental activities that lead to drop out and investment in sport. Physical Education and Sport Pedagogy, 12, 77-87. 